\title{
Studies on Nucleolus and Nucleolar Chromosomes in Angiosperms IX. Lilium Linn.
}

\author{
Anima Langer and A. K. Koul \\ Department of Biosciences, University of Jammu, \\ Jammu-180001, India
}

Received September 8, 1981

Although majority of plants bear single nucleolus per nucleus and one nucleolar chromosome per monoploid set, examples of higher numbers are also quite frequent. In Bellevalia dubia, six out of a total of eight chromosomes are involved in nucleologenesis (Maggini and De Dominicis 1977). In animal kingdom as well, highly evolved taxa, Homo sapiens included, have more than one nucleolar chromosome per monoploid set. Whenever the nucleus contains more than one nucleolar chromosome, are all these functionally potent. Diverse views have been expressed on this issue. Sato (1936) and Fernandes (1936) opine that all secondary constrictions do not necessarily function as nucleolus organizers. But, recent studies on a variety of angiosperms reveal positive correlation between number of secondary constrictions and nucleoli, which implies that all secondary constrictions are potential in the organization of nucleolus. In such a situation, do all NOR's function simultaneously in various tissues of an organism? Rabbit (Martin-De Leon et al. 1978) and man (Hubbell and Hsu 1977) demonstrate variation between various tissues in transcriptionally active NOR's. An attempt towards seeking solutions to these problems was made in four species of Lilium (family Liliaceae).

\section{Materials and methods}

Four species namely, L. regale Wils., L. roseum Wall, L. thomsonianum Royle and $L$. tigrinum Ker-Gawl constitute the material for present work. Material of the first three species was collected from localities of Srinagar (Kashmir), but that of L. thomsonianum was procured from Garhwal (U. P.).

For karyology, healthy root tips were first pretreated with a saturated solution of para-dichlorobenzene for $4 \mathrm{hrs}$. and then fixed in acetic ethanol (1:3) for $24 \mathrm{hrs}$. Squashes were prepared through conventional Feulgen staining schedule.

For microsporogenesis, young flower buds were directly fixed in acetic ethanol $(1: 3)$ for 24 hrs. Anthers of buds thus fixed were later squashed in $1 \%$ acetocarmine.

Nucleolar number was determined from root tips and flower buds fixed in Rattenbury's fluid (1952) for three days. Root tips, ovaries and anthers were separately hydrolysed in $\mathrm{NHCl}$ for $2 \mathrm{hrs}$ at $60^{\circ} \mathrm{C}$ and then placed in $1 \%$ acetocarmine until they got stained. Squashing was carried out in $1 \%$ acetocarmine. 


\section{Observations}

\section{Lilium regale}

1. 1. Karyotype: All well spread metaphase plates of the root meristem possess a total of 24 chromosomes; of these eight are submedian and the rest subterminal (Figs. 1-3). Arm ratio of the chromosomes comprising the latter group ranges from 3.4 to 18.5 . Eight chromosomes bear secondary constriction; of these four each are

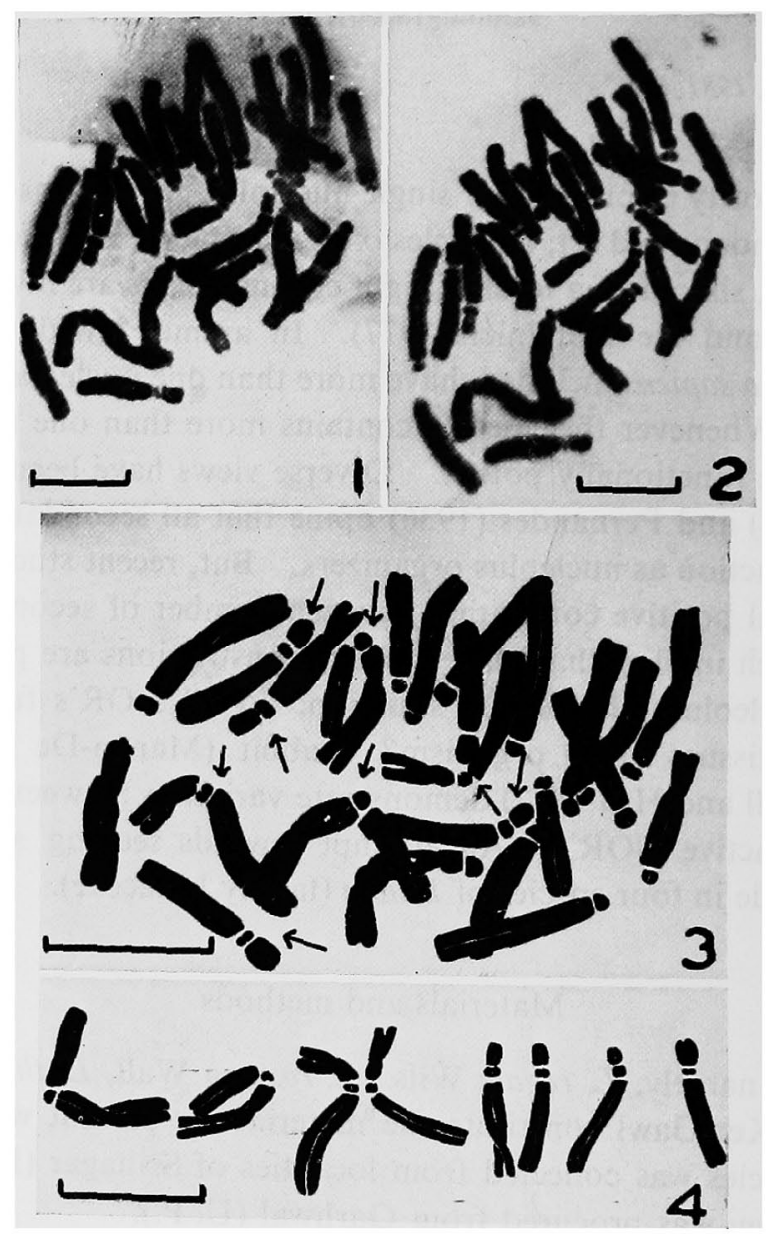

Figs. 1-4. Somatic complement and nucleolar chromosomes of Lilium regale. Scale $10 \mu . \quad 1$ and 2 , microphotographs of same metaphase plate to show different nucleolar chromosomes. 3, camera lucida drawing of cell in Figs. 1 and 2. 4, nucleoar chromosomes from the same cell.

of submedian and subterminal types. Six of the eight chromosomes bearing secondary constriction match into pairs, but the remaining two are heteromorphic (Fig. 4). The longest and shortest members of the chromosomes complement measure 20.7 and $9.3 \mu$ respectively; the ratio approaching 2.2 .

1. 2. Nucleolus: Data based on 973 root tip interphase nuclei reveal a maximum of eight nucleoli per nucleus; three and four are, however, the most frequent numbers (Figs. 5-7). Cells bearing maximum and minimum numbers are least frequent (Table 1). Like root tip cells, nuclei of anther wall cells and nucellus too 
possess a maximum of eight nucleoli; tetra- and pentanucleolate nuclei being most frequent (Fig. 8). Pollen grain nuclei carry one to four nucleoli each. Numerical uniformity notwithstanding, nucleolar size varies a great deal in cells of different organs. A summary of nucleolus size and number in different tissues of Lilium regale is presented in Table 2 .

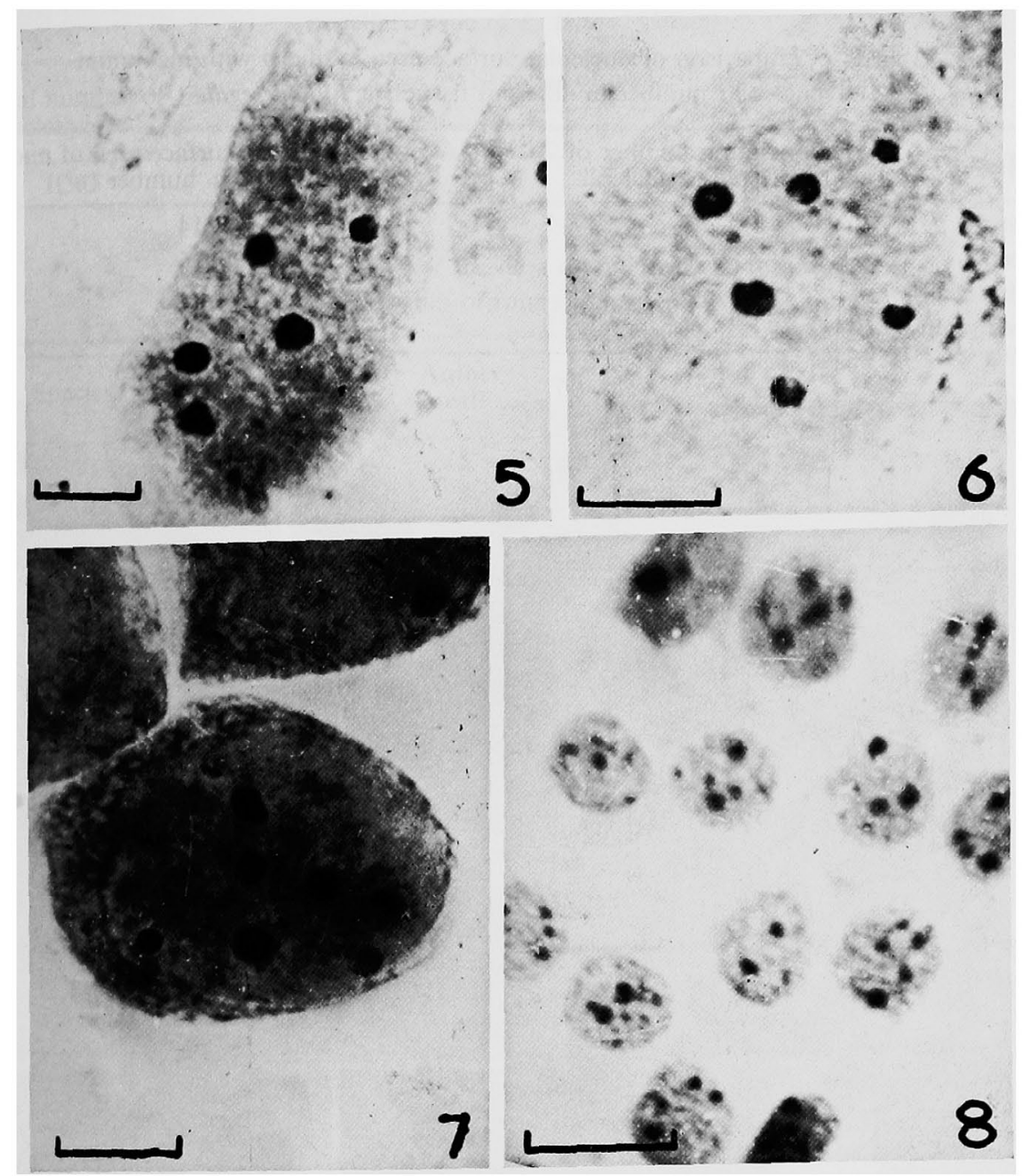

Figs. 5-8. Scale $10 \mu$. 5 to 7 , five, six and seven nucleolate root itp nuclei of Lilium regale. 8 , a part of nucellar tissue of Lilium regale to show multinucleolate condition of nuclei.

2. L. thomsonianum: The organs screened for nucleolar number are nucellus, anther wall, pollen grains and developing embryo sacs. The maximum number of nucleoli organized per nucleus of the nucellus and anther wall is eight; nuclei with four to six nucleoli are most frequent (Figs. 9 and 10). Table 3 contains data on percentage frequency of the nucellar nuclei bearing different nucleolar numbers. As expected, pollen grains carry a maximum of four nucleoli per nucleus.

Nuclei of the bi- and primary four-nucleate embryo sacs have 1-4 nucleoli each (Fig. 11). During embryo sac ontogeny, which conforms to "Fritillaria type", 
Table 1. Percentage frequency of nuclei with varying nucleolar numbers in root meristem of $L$. regale

\begin{tabular}{ccccccccc}
\hline \multirow{2}{*}{$\begin{array}{c}\text { Total no. of nuclei } \\
\text { scored }\end{array}$} & \multicolumn{7}{c}{ Number of nucleoli per nucleus } \\
\cline { 2 - 9 } & 1 & 2 & 3 & 4 & 5 & 6 & 7 & 8 \\
\hline 973 & 0.92 & 9.96 & 26.6 & 29.9 & 20.8 & 7.19 & 3.28 & 1.23 \\
\hline
\end{tabular}

Table 2. Comparison of nucleolar surface area in nuclei with maximum nucleolar number in different tissues of Lilium regale

\begin{tabular}{lcc}
\hline Tissue & $\begin{array}{c}\text { Maximum number of } \\
\text { interphase nucleoli }\end{array}$ & $\begin{array}{c}\text { Average nucleolar surface area of nuclei } \\
\text { with max. nuc. number }\left(\mu^{2}\right)\end{array}$ \\
\hline Root tip & 8 & 242.14 \\
Nucellus & 8 & 39.16 \\
Anther wall & 8 & 47.03 \\
Pollen grain & 4 & 84.23 \\
\hline
\end{tabular}

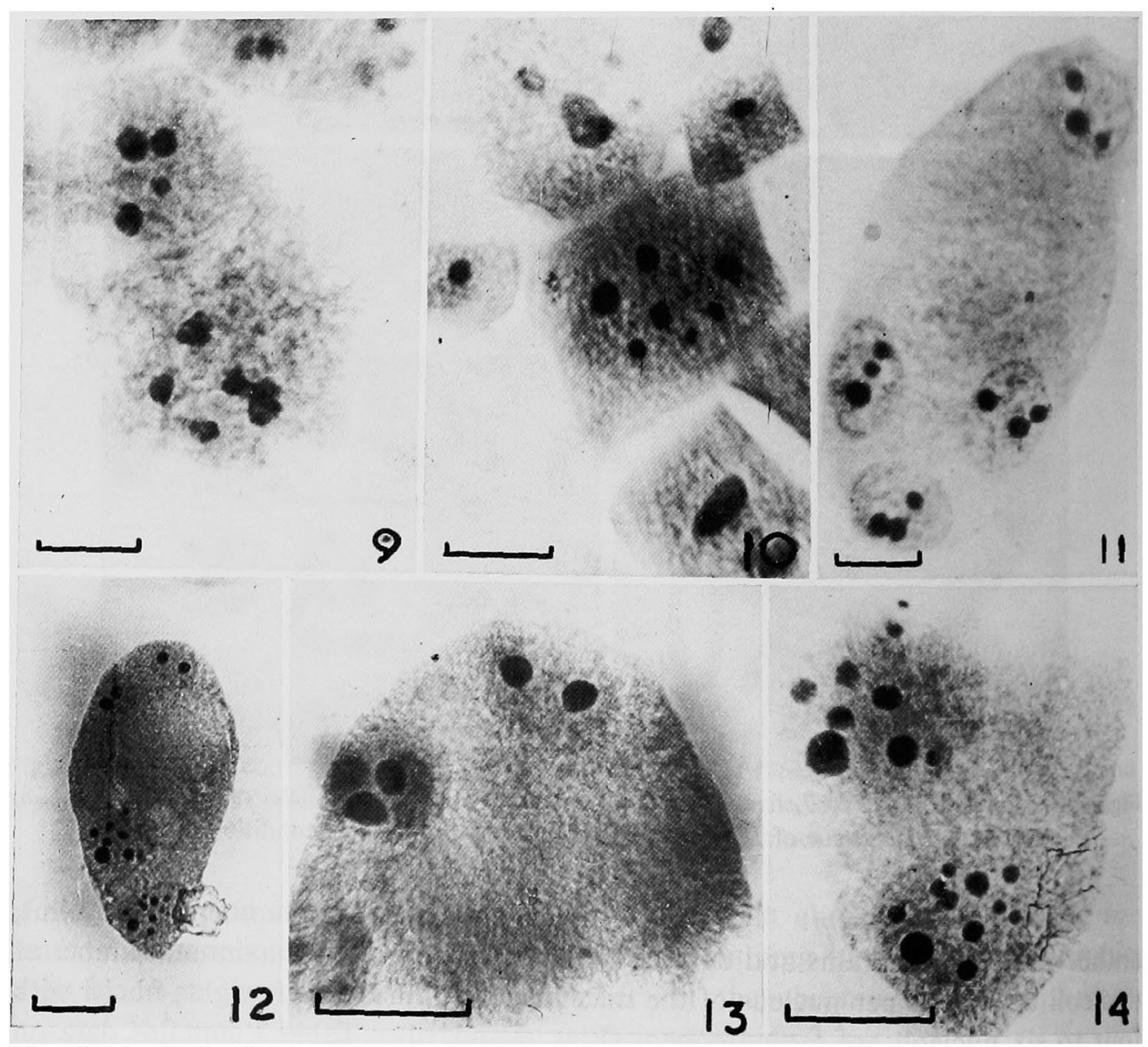

Figs. 9-14. Scale $10 \mu$. 9 and 10, nuclellar cells of Lilium thomsonianum at interphase, to show penta- and hepta-nucleolate nuclei. 11, a primary 4-nucleate embryo sac of Lilium thomsonianum, all nuclei are trinucleolate. 12 to 14, a secondary 4-nucleate embryo sac (Fig. 12) and parts thereof (Figs. 13 and 14). Both haploid nuclei and binucleolate while those at opposite pole are 7- and 11-nucleolate. 
metaphase spindles of three haploid nuclei of the primary 4-nucleate embryo sac fuse and produce a single triploid nucleus at the chalazal end. Subsequent developmental stages of such an embryo sac provide opportunity to compare nucleolar condition in haploid and triploid nuclei contained within the same coenocyte. The

Table 3. Percentage frequency of nuclei with varying nucleolar numbers in nucellar tissue of $L$. thomsonianum

\begin{tabular}{cccccccccc}
\hline \hline \multirow{2}{*}{$\begin{array}{c}\text { Total number of } \\
\text { nuclei scored }\end{array}$} & 1 & 2 & 3 & 4 & 5 & 6 & 7 & 8 \\
\cline { 2 - 9 } & 1.3 & 3.3 & 14.6 & 22.6 & 25.8 & 18.5 & 9.6 & 0.51 \\
\hline 1,355 & & &
\end{tabular}

Table 4. Summary of the data on nucleolar condition in various tissues of four species of Lilium

\begin{tabular}{lcccccc}
\hline \hline \multicolumn{1}{c}{ Species } & $\begin{array}{c}\text { Root } \\
\text { tip }\end{array}$ & $\begin{array}{c}\text { Anther } \\
\text { wall }\end{array}$ & Nucellus & $\begin{array}{c}\text { Pollen } \\
\text { grain }\end{array}$ & \multicolumn{2}{c}{ E. sac } \\
\hline L. regale & 8 & 8 & 8 & 4 & - & (X) \\
L. thomsonianum & - & 8 & 8 & 4 & 4 & 12 \\
L. roseum & - & 8 & 8 & - & - & - \\
L. tigrinum & - & 8 & 8 & - & - & - \\
\hline
\end{tabular}
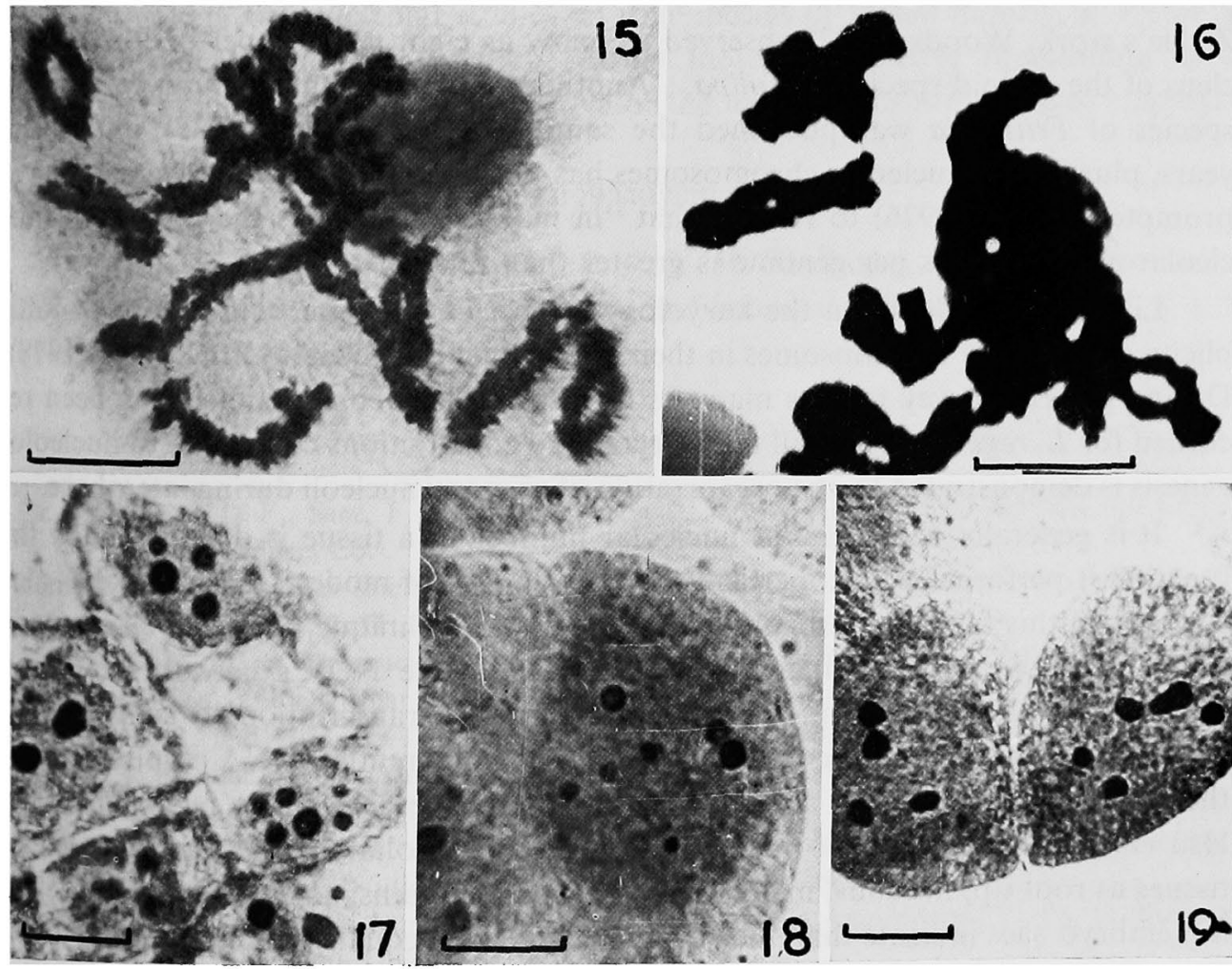

Figs. 15-19. Scale $10 \mu, 15$ and 16, microsporocytes of Lilium roseum at late prophase. Note the 4-nucleolar bivalents. 17 and 18, cells from anther wall of Lilium roseum bearing multinucleolate nuclei. 19 , nucellar cells of $L$. roseum bearing terta- and pentanucleolate nuclei. 
maximum and average number of nucleoli per haploid nucleus of such a coenocyte is 4 and 2.95 respectively (Figs. 12 and 13). The triploid nuclei on the contrary contain a maximum of eleven (Figs. 12 and 14) and average of 9.37 nucleoli.

3. L. roseum: Cells of nucellus, anther wall and microsporocytes were employed for establishing relationship between number of nucleoli and the chromosomes organizing them. In 24 of the 37 microspore mother cells studied at prophase-I, four bivalents were observed attached to the nucleolus (Figs. 15 and 16). In interphase nuclei of anther wall cells and the nucellus, number of nucleoli is high, which is strongly in accordance with the number of nucleolar bivalents observed in microsporocytes (Figs. 17-19).

4. L. tigrinum: Nucleolar number for L. tigrinum was determined from cells of the anther wall and nucellus. Like other species of the genus, this one too bears a maximum of eight nucleoli per nucleus.

Table 4 summarizes data raised on nucleolar condition in the four species of Lilium surveyed during present work.

\section{Discussion}

As early as 1931, Zirkle recorded ten nucleoli per diploid nucleus of Pinus strobus. For want of parallel observations in angiosperms at the time, he treated nucleolar plurality as a feature, typical of the gymnosperms. But only within a few years of Zirkle's work, Woods (1937) observed as many as eight nucleoli per interphase nucleus of the diploid species of Tulipa. Another report of similar nature, concerning species of Fritillaria was published the same year by Frankel (1937). Over the years, plurality of nucleolar chromosomes has turned to be so widespread as to have prompted Ghosh (1976) to remark that "in majority of species the number of nucleolar chromosomes per genome is greater than one".

Literature available on the karyology of species of genus Lilium reveals multiplicity of nucleolar chromosomes in their complements (Noda 1975, 1978, Sen 1978). During present survey too, as many as eight secondary constrictions have been recorded for $L$. regale. That, all these secondary constrictions contribute to nucleologenesis is demonstrated by the organization of as many nucleoli during interphase.

It is generally believed that nucleolar number of a tissue is determined by the function it performs (De Robertis et al. 1975). Use of modern techniques has also established this fact. By resorting to silver-staining technique, Martin-De Leon et al. (1978) found remarkable difference in number of active NOR's between blastocyst and kidney fibroblast nuclei. Variation in number of transcriptionally active NOR's from one cell type to another has been ascribed to differential rRNA requirements of the various body tissues. Similar observations have been made by Hubbell and Hsu (1977) in human cells. Data collected on nucleolar number from as diverse tissues as root tip, nucellus, microsporocytes, pollen grains, anther wall and developing embryo sacs indicate that nucleolus organizers are equally potent in all cell types. The effect caused by the metabolic state of a cell is, however, reflected in nucleolar size (see Table 2). Simultaneous functioning of NOR's in different cell types also receives support by the unfailing correlation between maximum nucleolar number 
organized per nucleus and its level of ploidy. Thus, while diploid nuclei (roo tip, anther wall, nucellus) bear a maximum of eight nucleoli, haploid nuclei of pollen grains and embryo sac bear half this number; triploid (chalazal nuclei of embryo sac) nuclei bear a proportionate higher number.

Another point brought out by present observations is that, species of Lilium uniformly bear a maximum of eight secondary constrictions and as many nucleoli (see Table 4). This uniformity is natural in view of comparable structural complexity and parallel evolutionary status of these species. On the contrary, a reverse trend obtains in allied genera such as Allium, Fritillaria etc. Some diploid species of Allium (all bearing a diploid complement of 16 chromosomes) vary drastically in number of NOR's. Against two in A. cepa, A. fistulosum, A. consanguineum etc. (Langer 1980), A. acutiflorum has 10 functional NOR's (Maggini and Garbari 1977). Species with four, six and eight NOR's per somatic complement are also on record (Maggini and Garbari 1977). Fritillaria imperialis and F. roylei agreeing in chromosome number $(2 n=24)$, differ in the number of NOR's; the former having four and the latter ten (Koul and Wafai 1980, Langer 1980). Why should species of equivalent evolutionary status and therefore, similar rRNA requirements exhibit, such a difference in NOR number is a question that awaits explanation.

\section{Abstract}

Karyology and nucleolar studies on four species of Lilium namely, $L$. regale, $L$. thomsonianum, L. tigrinum and $L$. roseum indicate collective functioning of all nucleolus organizing regions irrespective of the nature of cells and tissue employed.

\section{Acknowledgements}

Necessary facilities provided by Prof. Y. R. Malhotra, Head, Department of Biosciences, University of Jammu, Jammu and financial aid received from C. S. I. R. (New Delhi) are gratefully acknowledged.

\section{References}

De Robertis, E. D. F., Saez, F. A. and De Robertis, E. M. F. 1975. Cell Biology, 6th Edition. W. B. Saunders Co.

Fernandes, A. 1936. Les satellites chez les Narcissus II. Les satellites pendent la mitose. Bot. Soc. Brot., Ser. 2. $11: 87-142$.

Frankel, O. H. 1937. The nucleolar cycle in some species of Fritillaria. Cytologia 8: 37-46.

Ghosh, S. 1976. The nucleolar structure. Int. Rev. Cytol. 44: 1-28.

Hubbell, H. R. and Hsu, T. C. 1977. Identification of nucleolus organizing regions (NOR's) in normal and neoplastic human cells by the silver staining technique. Cytogenet. Cell. Genet. 19: 185-196.

Koul, A. K. and Wafai, B. A. 1980. Chromosome polymorphism and nucleoar organization in some species of Fritillaria Linn. Cytologia 45: 675-682.

Langer, A. 1980. "Studies in nucleolar organization in some Angiosperms". Ph. D. thesis approved by Jammu University.

Maggini, F. and De Dominicis, R. S. 1977. The ribosomal RNA gene number and the length of the nucleolar secondary constriction in Bellevalia romana and B. dubia (Liliaceae). A possible correlation. Caryologia 30: 97-103. 
- and Garbari, F. 1977. Amounts of ribosomal DNA in Allium (Liliaceae). Plant Syst. Evol. 128: 201-298.

Martin-De Leon, P. A., Fleming, M. E. and Pertosky, D. L. 1978. Patterns of silver staining in cells of six day blastocyst and kidney fibroblast of the domestic rabbit. Chromosoma 67: $245-252$.

Noda, S. 1975. Somatic origin of chromosome aberrations in Scilla scilloides and Lilium tigrinum. Bull. Cult. Nat. Sci. Osaka Gakuin Univ. No. 1: 97-104.

- 1978. Chromosomes of diploid and triploid forms in the natural populations of tiger lily in Tsushima. Bot. Mag. 91: 279-283.

Rattenbury, J. A. 1952. Specific staining of nucleolar substance with acetocarmine. Stain Technol. $27:$ 113-120.

Sato, D. 1936. Chromosome studies in Scilla III. Sat-chromosomes and the karyotype analysis in Scilla and other genera. Cytologia $7: 521-529$.

Sen, S. 1978. Intraspecific differentiation in karyotype of Lilium. Cytologia 43: 305-315.

Woods, M. W. 1937. The nucleolus in Tulipa. Amer. Jour. Bot. 24: 528-536.

Zirkle, C. 1931. Nucleoli of the root tip and cambium of Pinus strobus. Cytologia 2: 85-105. 